\title{
DIALECTOLOGÍA TRADICIONAL, SOCIOLINGÜÍSTICA LABOVIANA Y GEOLINGÜÍSTICA TRUDGILLIANA: TRES APROXIMACIONES AL ESTUDIO DE LA VARIACIÓN
}

\author{
J. M. HeRnández CAMpoy \\ (Universidad de Murcia)
}

\begin{abstract}
RESUMEN
Traditional Dialectology, Labovian Sociolinguistics and Trudgillian Geolinguistics represent in themselves three different approaches to the same concern: variation phenomena and linguistic change. Although sometimes the renewing impetus of some scholars provoked extremely discrediting positions against some linguistic studies from the past -particularly against those related to dialectological work-, in a new era of co-operation, integration and synthesis in the field as the one that dominates the studies in Language and Society nowadays, these three approaches to 'variationism' can be considered as complementary, regardless of the extent of sophistication they enjoy or might have enjoyed. The aim of this paper is to provide a general view of Traditional Dialectology, Labovian Sociolinguistics and Trudgillian Geolinguistics, discussing the nature of their relationships.
\end{abstract}

\section{LA DIALECTOLOGÍA TRADICIONAL}

Desde que Georg Wenker inició el primer estudio dialectológico moderno en Alemania en 1876, y a pesar de las distintas interpretaciones fundadas en presupuestos ya historicistas, ya estructuralistas o ya generativistas, la Dialectologia se ha venido ocupando del «estudio del dialecto y los dialectos» (Chambers \& Trudgill 1980: 3). Con el estudio sistemático de los dialectos regionales, concretamente de su descripción, aquellas palabras geográficamente diferentes - ya en forma, sentido, o pronunciación - han constituido siempre todo el centro de atención de los dialectólogos, quienes las recogían y visualizaban 
en atlas linguísticos. El trabajo de Wenker tuvo como resultado el primer atlas dialectal publicado, Sprachatlas des Deutchen Reichs (1881) y posteriormente el Deutcher Sprachatlas (DSA, 1926-1956). A partir de éste, el perfeccionamiento de la metodología y técnicas de recogida de datos y análisis fue cada vez más evidente, dentro de lo que las limitaciones históricas, sociales y tecnológicas permitían: si el trabajo de Wenker era 'por correo', haciendo uso de un cuestionario remitido a los informantes, en Francia, el de Jules Gilliéron y Edmond Edmont, que dio lugar al Atlas Linguistique de la France (ALF, 1902-1910), era 'a domicilio', un método directo con visitas llevadas a cabo por investigadores de campo especializados, y haciendo uso de otras innovaciones como el empleo de una notación fonética sistemática.

Estudios nacionales similares a los iniciales de Alemania y Francia se llevaron a cabo en numerosos países: los Estados Unidos y Canadá tienen como su máximo exponente el Linguistic Atlas of the United States and Canada (LAUSC), coordinado por Hans Kurath y comenzado en 1939, además de otros realizados sobre áreas específicas como el Linguistic Atlas of New England (LANE), Linguistic Atlas of the Upper Midwest (LAUMW), Linguistic Atlas of the Middle and South Atlantic States (LAMSAS), Linguistic Atlas of the North Central States (LANCS), A Word Geography of the Estern United States (WGEUS), y el Linguistic Atlas of the Gulf States; en Inglaterra pueden destacarse el Survey of English Dialects (SED), ideado por Eugen Dieth de Zurich y Harold Orton de Leeds y comenzado en 1948, del que se sirvieron el Phonological Atlas of the Northern Region (PANR) y A Word Geography of England (WGE), y el trabajo más reciente The Linguistic Atlas of England (LAE), llevado a cabo por Harold Orton, Stewart Sanderson y John Widdowson en 1978; en Italia y el sur de Suiza Karl Jaberg y Jakob Jud realizaron el Sprach- und Sachatlas des Italiens und der Südschweiz (AIS), 1928-1940; en España fue pionero A. Griera con su Atlas Lingüistic de Catalunya (ALC), comenzado en 1924 y posteriormente integrado en el Atlas Lingüístico de la Península Ibérica (ALPI), coordinado por Tomás Navarro Tomás'; además de otros muchos países como Rumanía, Dinamarca, Noruega, Gales, Escocia, etc.

Cuando Georg Wenker planificó su Sprachatlas des Deutchen Reichs su objetivo principal era establecer las fronteras, los límites, de los dialectos alemanes. Es decir, en el contexto de la Neogramática, y por consiguiente asumiendo i) que los dialectos eran entidades discretas, ii) que los hablantes eran o bien hablantes de un dialecto determinado o no, y iii) que ciertamente existen las fronteras dialectales, los dialectólogos empezaron a trazar isoglosas -la principal creación teórica de la Dialectología Tradicional- en mapas para repre-

Para una descripción más pormenorizada sobre los atlas linguísticos realizados en la Península Ibérica y su situación, véase Manuel Alvar (163; 1968 y 1973) o Francisco Gimeno Menéndez (1990). 
sentar la discontinuidad de las áreas dialectales: las palabras y las pronunciaciones no estaban distribuidas aleatoriamente sino confinadas en regiones determinadas. Si bien en términos más rigurosos las isoglosas son líneas trazadas en mapas para separar las áreas geográficas que tienen determinados usos de palabras de aquellas que no y los isofonos marcan los límites de los rasgos fonológicos, frecuentemente, sin embargo, se utiliza el término 'isoglosas' en ambos casos (Trudgill 1975: 232); Estas se estructuran conforme al tipo de rasgo linguiístico que describen: isoglosas léxicas, de pronunciación (fonéticas y fonémicas), gramaticales (morfológicas y sintácticas) y semánticas (Chambers \& Trudgill 1980: 112-6). Así, un ejemplo de isoglosas, concretamente léxicas, es el de la visualización en mapas de la distribución geográfica de diferentes elementos léxicos que significan 'chica' ('girl') en Inglaterra según el Survey of English Dialects:

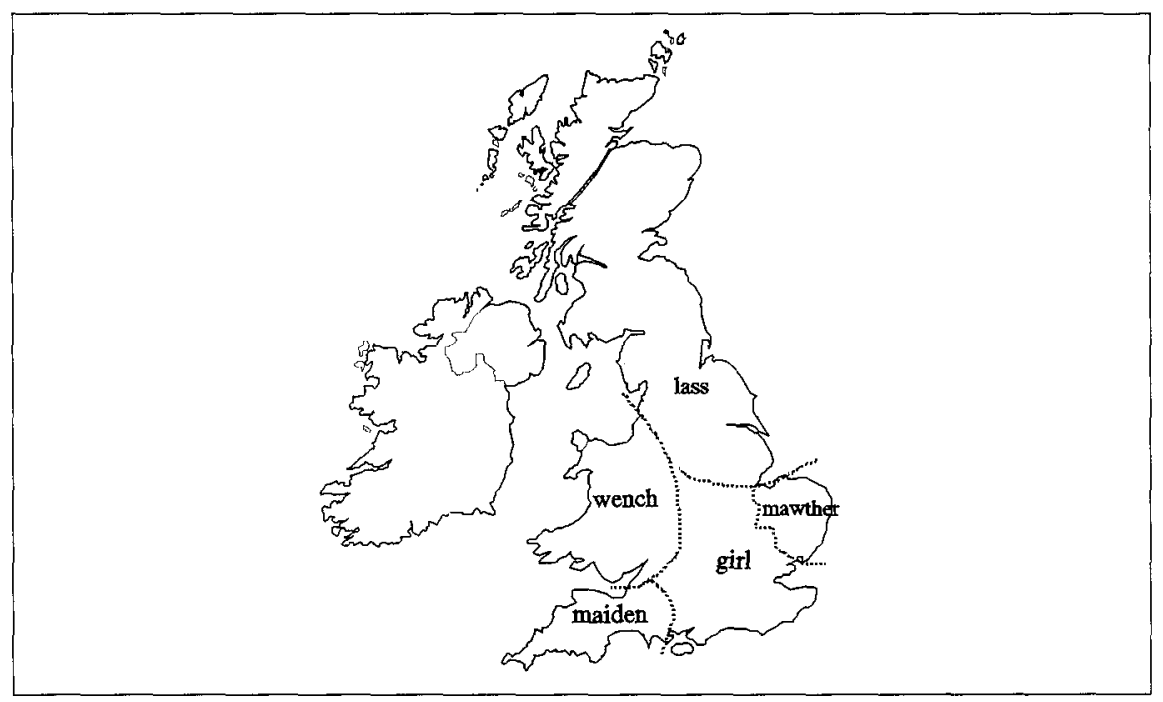

Ilustr. 1 Distribución geográfica de las variables léxicas referidas a 'chica' en GB según el $S E D$.

Aunque el origen de la palabra girl es desconocido, tiene reconocida una antigüedad que se remonta al año 1200; lass es probablemente una palabra de origen escandinavo y su uso está recogido desde el año 1300; mawther, también es muy probablemente una palabra de raíces escandinavas y de la que se tiene constancia desde aproximadamente el año 1450; maiden es un vocablo del anglo-sajón y por consiguiente su uso se remonta a los mismos orígenes del 
inglés; y la palabra wench es un término también de origen anglo-sajón cuyo uso se remonta aproximadamente al año 1300 ( $c f$. Trudgill 1990: 115-17). Un ejemplo de diferenciación geográfica en la pronunciación es el caso de la $/ \mathrm{r} /$ postvocálica en Inglaterra en palabras como car, siendo pronunciada [ka:r] por los acentos róticos y [ka:] por los no róticos:

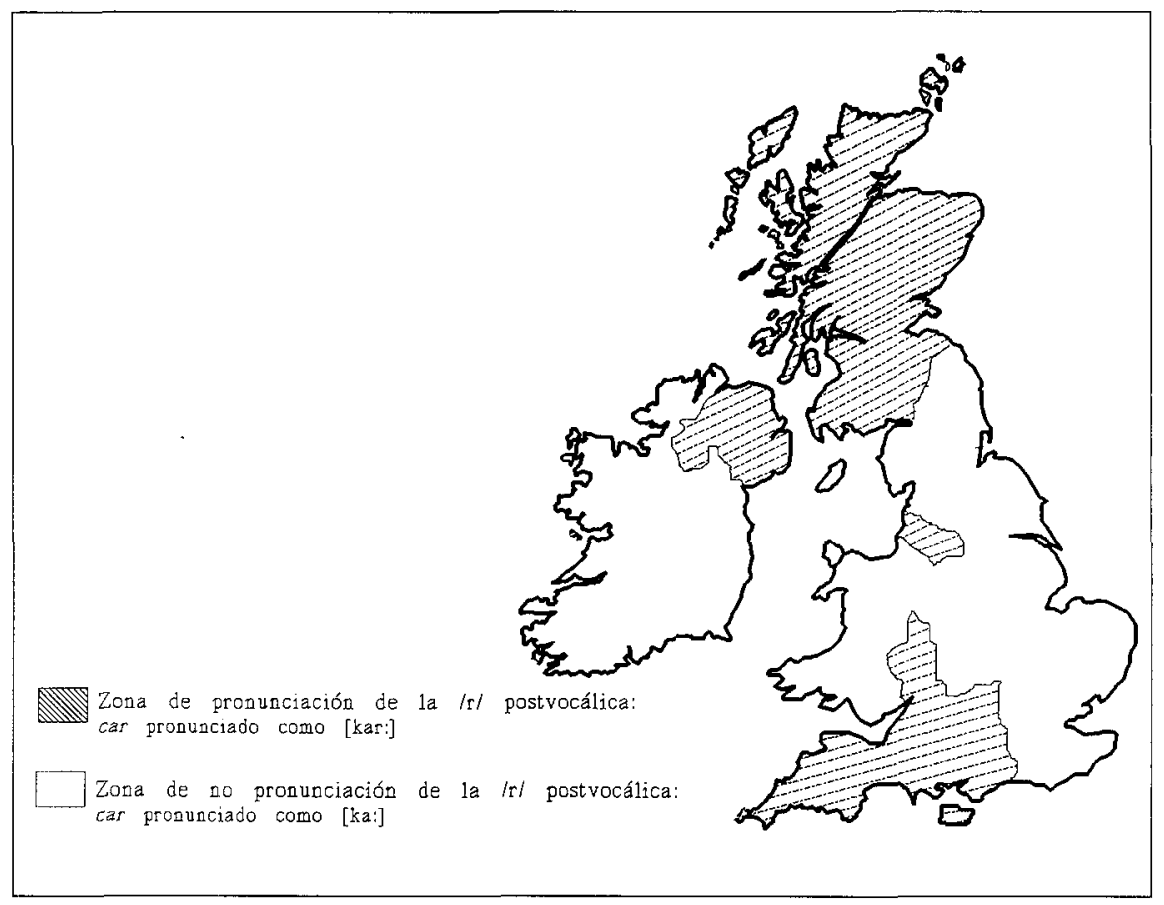

Ilustr. 2 Fenómeno del Rotacismo en Gran Bretaña: pronunciación de la $/ \mathrm{r} /$ postvocálica

Este proceso de pérdida de una /r/ histórica en posición postvocálica se remonta al siglo XVIII, originando una distinción entre acentos róticos, aquellos que todavía conservan esa/r/en la pronunciación de palabras como car, four, far, lord, etc., y acentos no róticos, aquellos que no conservan ese rasgo ( $c f$. Wells 1982 y Trudgill 1990). Un ejemplo de isoglosa gramatical es el uso de diferentes pronombres personales en diferentes dialectos para la segunda persona del singular, usos que tienen su origen en los antiguos dialectos tradicionales (cf. Trudgill 1990 y Trudgill \& Chambers 1991): 


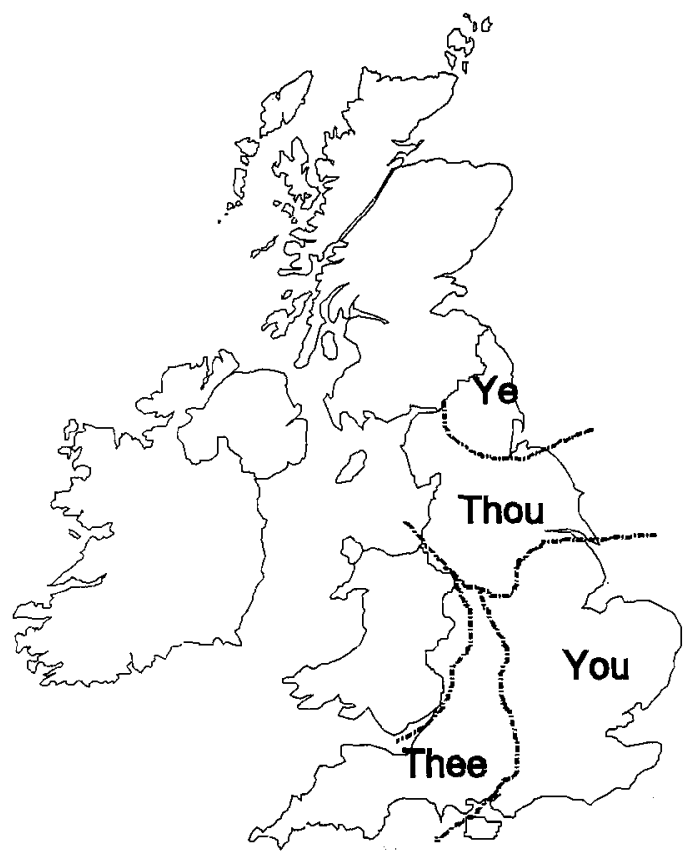

Ilustr. 3 Distribución geográfica de las variables gramaticales referidas a la $2^{a} \mathrm{p}$. $\mathrm{sg}$. del pronombre personal en GB

Según el tipo de isoglosas que visualizaban, los mapas lingüísticos ofrecidos en los atlas dialectales podían ser mapas léxicos, de pronunciación, gramaticales, semánticos e incluso lingüístico-etnográficos. Al mismo tiempo, según la información ofrecida, éstos podían ser bien descriptivos o bien interpretativos. Los primeros son los más comunes y «simplemente transfieren las respuestas contabilizadas de un rasgo determinado a un mapa, situando la contabilización en una perspectiva geográfica», mientras que los segundos, los mapas interpretativos, «intentan ofrecer una mayor información general que los descriptivos, mostrando la distribución de las variantes predominantes de una región a otra» (Chambers \& Trudgill 1980: 28-33).

El afán de búsqueda de los dialectos 'puros' o 'reales' provocó que en todos estos estudios la selección de los hablantes se hiciera atendiendo a ciertas características que éstos tenían que cumplir, independientemente de las realia, esto es, de las diferencias culturales, socioeconómicas y topográficas. Estos requisitos son los que Chambers \& Trudgill (1980: 33) etiquetaron con las siglas NORMs, nonmobile older rural male speakers: los informantes debían ser hablantes nonmobile — no ambulantes- (para garantizar que su habla era 
característica de la región en la que vivían), older -mayores- (para reflejar el habla de una época antigua), rural -rurales- (porque allí las innovaciones eran más improbables), y male — varones- (porque el habla de la mujer tendía, o tiende, a ser más insegura y a tener más conciencia de clase que la de los hombres) $)^{2}$.

Sin embargo, la situación real era mucho más complicada de lo que todos estos presupuestos neogramáticos defendían, y de hecho, desde finales del siglo XIX y principios del XX, la cuestión de la distintividad de los dialectos, o de la existencia de tales fronteras, era un tema que provocaba intensas discusiones entre los filólogos del momento. Cuando los mapas que mostraban rasgos individuales eran fusionados para hacer visualizaciones globales que incluyeran una serie de diferencias dialectales, los dialectólogos, bastante contrariados, descubrían no sólo que en realidad únicamente unas pocas isoglosas coincidían, sino incluso que se entrelazaban de manera al parecer casual. Por ejemplo, en Inglaterra un hecho muy conocido es que los hablantes del sur del país pronuncian los pares de palabras tales como put/putt y could/cud con vocales diferentes $(/ \mathrm{u} /$ y $/ \wedge /$ respectivamente en cada par), y palabras como path, dance y past con una $a$ larga $(/ a: /)$, mientras que los hablantes de las variedades del inglés del norte no distinguen entre put o could y putt o cud (las pronuncian todas como / $\mathrm{u} /$ ) y emplean una $a$ breve $(/ \mathfrak{x} /)$ en path, dance, etc. Sin embargo no es posible dividir Inglaterra simplemente en dos áreas dialectales principales, el norte y el sur, según estas características, puesto que, en su mayor parte, la isoglosa de put/putt no coincide con la de path, e incluso hay áreas en las que los hablantes pronuncian /a:/ en dance pero /æ/ en past:

2 Una panorámica general muy completa y precisa sobre el tratamiento de los grupos de edad en los estudios hispánicos es la que ofrece el trabajo de José María Jiménez Cano (1992). 


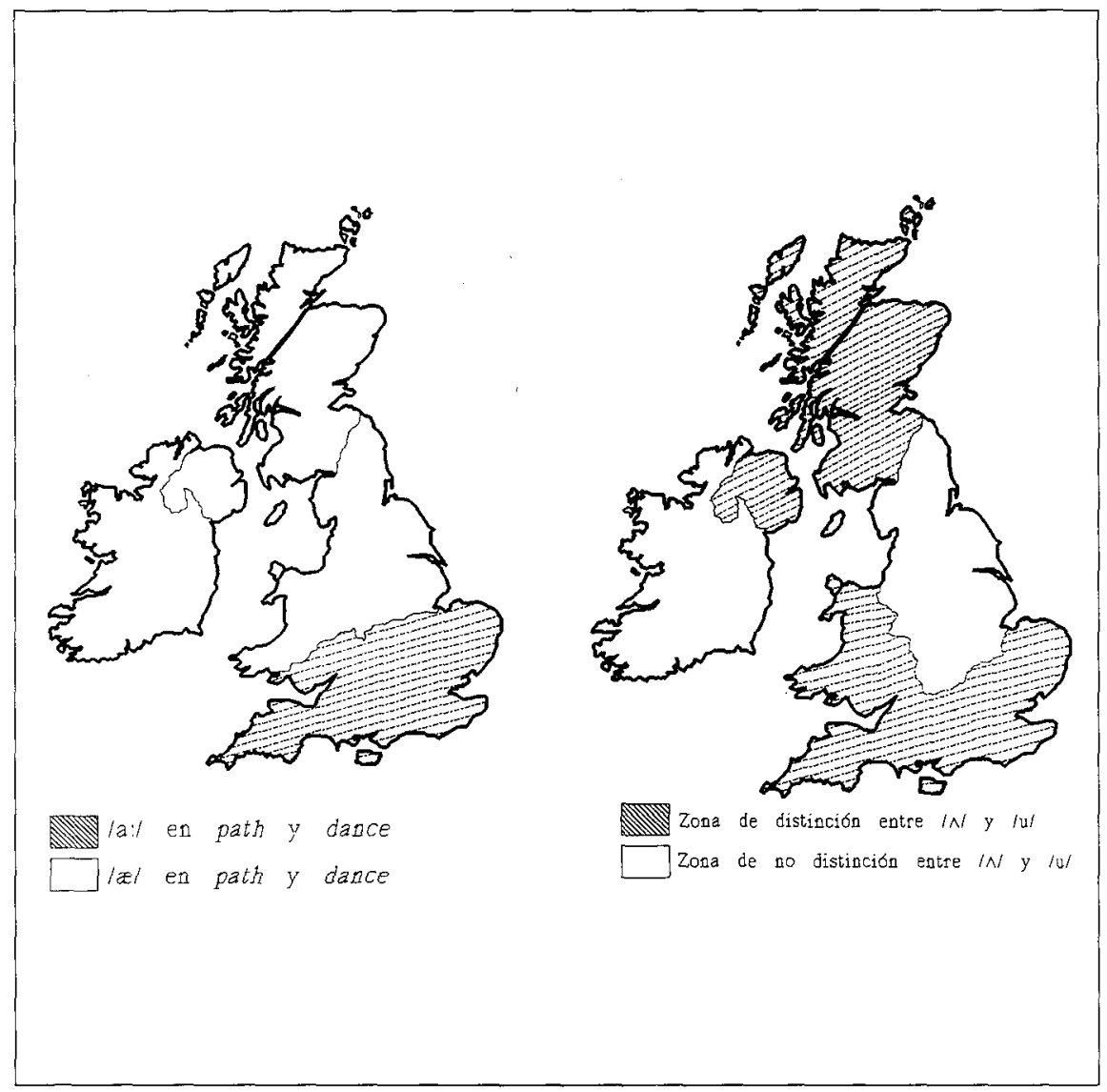

Ilustr. 4 Pronunciación de path y dance y distinción entre $/ U / \mathrm{y} / \curvearrowright /$ en pares como put/putt en GB

Poco a poco lo que descubrieron fue que los cambios fonéticos pueden aparecer perfectamente de modos muy distintos en lugares también diferentes y que los dialectos no son entidades discretas en absoluto. Como las fronteras dialectales, en cuanto tales, no podían localizarse, una reacción inicial fue la de sugerir que no existían los dialectos. Con el tiempo fue posible detectar unos modelos en los mapas dialectales y los dialectólogos pudieron explicar determinados fenómenos que tendían a repetirse en todos ellos: núcleos centrales, áreas focales, áreas de transición, haces de isoglosas, cuñas de avance y áreas remanentes; la siguiente figura es un ejemplo de un área dialectal: 


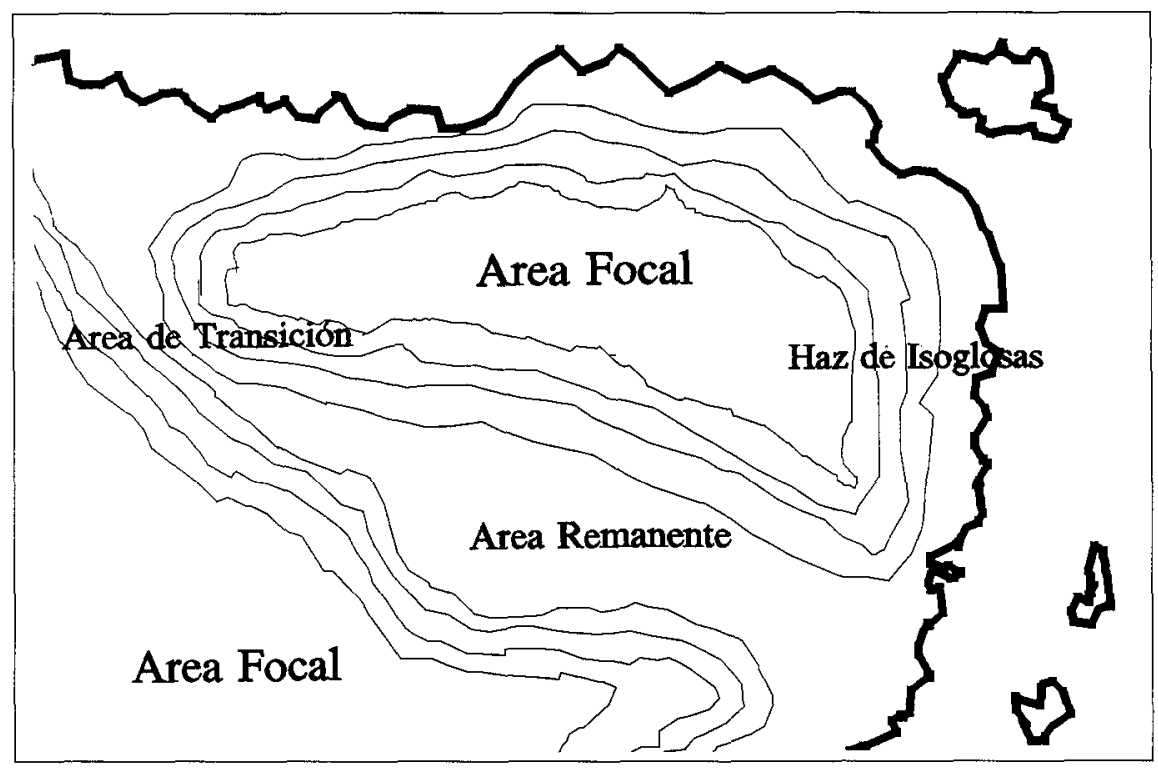

Ilustr. 5 Ejemplo de un área dialectal

En las áreas dialectales hay núcleos centrales, los núcleos urbanos, que son el centro de un área focal, también llamada área central, los núcleos dialectales. Las áreas focales estaban rodeadas bien por áreas de transición, que estaban atravesadas por muchas isoglosas y no pertenecían de modo claro a ningún área focal, o bien por haces de isoglosas, series de isoglosas circulando muy juntas en la misma dirección de tal modo que se asemejan a una auténtica frontera dialectal. Estas fronteras dialectales no existen como líneas definidas sino como áreas de transición dentro de un continuum dialectal, esto es, la mayoría de las diferencias dialectales son graduales más que abruptas, como los colores del arco iris: «En realidad no existen los dialectos y por tanto tampoco las fronteras dialectales; en lugar de eso, lo que sí hay es un cambio gradual continuo y acumulativo a través del campo. No hay ningún corte en la cadena de intercomunicación de un área a otra, sino que, por el contrario, una acumulación de diferencias que al final se traduce en ininteligibilidad entre ambos extremos de la cadena. La paradoja es que hay diferencias dialectales en los extremos, pero entre ambos sólo hay un área de transición continua sin límites y sin 'dialectos locales' propios» ( $c f$. Francis 1983: 152) $)^{3}$. A esta situación se la co-

Esta es la razón por la que, en cierta ocasión, Trudgill (1983a) afirma que «un alemán viviendo cerca de la frontera con Holanda puede entender más fácilmente a un visitante procedente de Amsterdam que de Munich». 
noce como continuum dialectal geográfico, y hay muchos de éstos en el mundo: en Europa, el Continuum dialectal del Románico Oeste se extiende desde la costa de Portugal hasta el centro de Bélgica y de allí al sur de Italia (con las variedades estándares del francés, italiano, catalán, español, y portugués, las cuales no son mutuamente inteligibles); otros son el Continuum del Germánico Oeste, que abarca a todos los dialectos normalmente conocidos como alemán, holandés, y flamenco; el Continuum Dialectal Escandinavo, que contiene a los dialectos del noruego, sueco, y danés; el Continuum Dialectal Eslavo Norte, que incluye al ruso, ukraniano, polaco, checo, y eslovaco; y el Continuum Dialectal Eslavo Sur, que comprende al esloveno, serbo-croata, macedonio, y búlgaro:

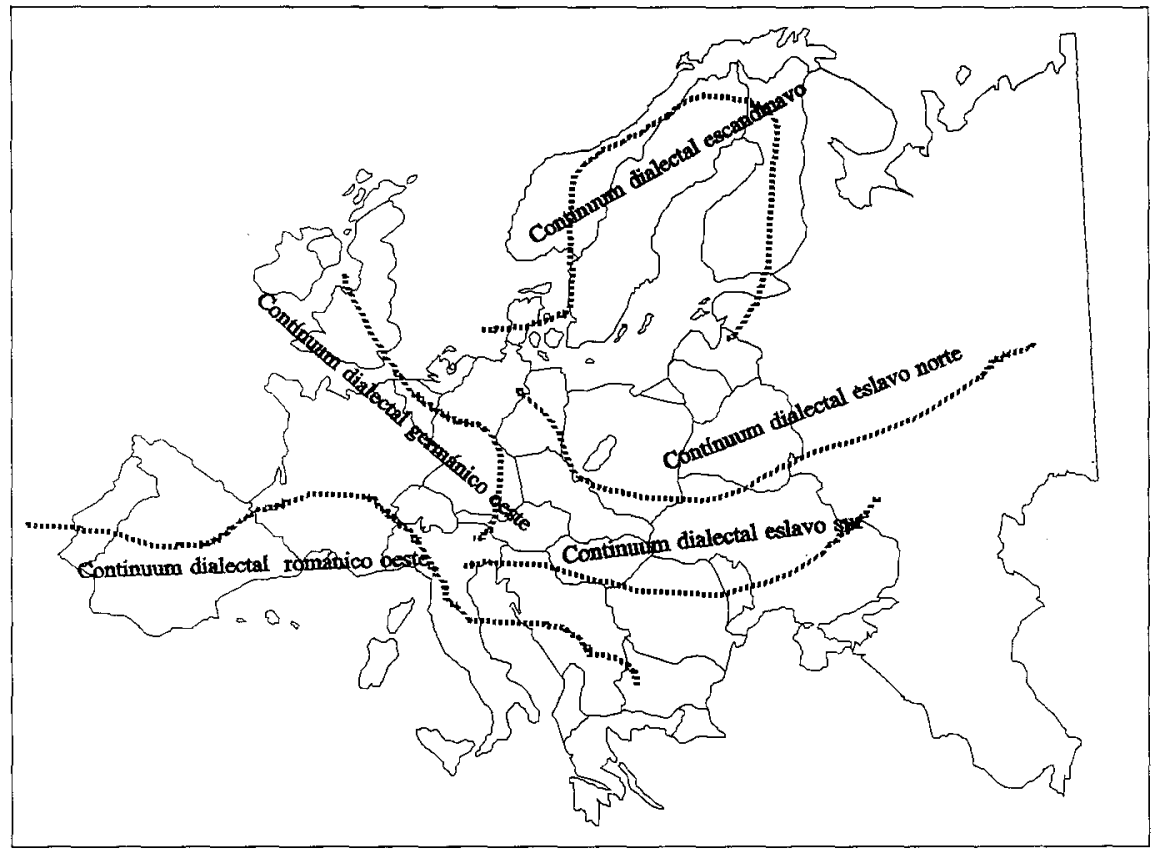

Ilustr. 6 Continuos dialectales geográficos en Europa

Trudgill (1986: 83-4) esboza las ramificaciones del continuum dialectal románico oeste en la Península Ibérica: «En la Península Ibérica, como es bien sabido, hay un continuum dialectal geográfico (véase Matias, 1984; Kurath, 1972) en el que los dialectos del catalán, español, y portugués se mezclan uno con otro gradualmente, y en el que el número de 'lenguas' reconocidas como habladas depende del número de variedades estándares, autónomas, que han 
logrado sobresalir del continuum dialectal. A los hablantes de los dialectos procedentes de la parte catalana del continuum se les considera generalmente, en estos días, hablantes de una lengua independiente del español/castellano, mientras que la aceptación del gallego como una lengua independiente es mucho más controvertida».

La existencia de estos continuos dialectales puede comprobarse, como indica Trudgill (1986: 63), con diferentes casos de formas lingüísticas intermedias $^{4}$, en este caso léxicas, en zonas de transición: «... tenemos el bien conocido ejemplo del dialecto alemán en el que un área donde 'patata' es grundbirne 'pera de tierra' está separada de otra donde es erdapfel 'manzana de tierra' por un área intermedia en la que la forma es erdbirne. Un ejemplo del mismo fenómeno en el inglés moderno es el uso de take away en el centro y sur de Inglaterra para referirse a los restaurantes chinos y a cualquier otro establecimiento en el que se puede comprar comida para llevar. Esta área del centro-sur de Inglaterra está dividida de una del norte (principalmente Escocia e Irlanda del Norte), donde se emplea el término carry out, por un área intermedia (parte del norte de Inglaterra) donde se emplea la forma intermedia take out». De este modo, aunque evidentemente los dialectos no se consideraron más como entidades discretas, eran válidos como unidades 'relativas': con respecto a los rasgos linguísticos tratados

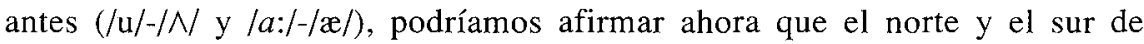
Inglaterra son, de modo inequívoco, áreas focales, mientras que las Midlands -la región central- es un área de transición.

De la configuración de determinadas isoglosas en mapas se observó que las formas lingüísticas se habían extendido evidentemente hacia el exterior como innovaciones procedentes de núcleos específicos. Estas difusiones de nuevas formas se hacían a modo de cuñas de avance dirigidas al interior de las áreas con formas antiguas, donde las áreas remanentes, territorios que conservan los rasgos lingüísticos de una etapa de desarrollo previa a la difusión de los nuevos, podían observarse como consecuencia de haber sido dejadas atrás y aisladas por dos cuñas de avance que se encuentran. Esos núcleos específicos, áreas focales, a partir de los que las innovaciones comenzaban a difundirse, eran generalmente núcleos urbanos o vías principales de comunicación, mientras que las áreas remanentes tendían a estar ubicadas en zonas aisladas como valles de montañas o en la distante periferia de las áreas lingüísticas. Las innovaciones lingüísticas también tendían a extenderse más lejos a lo largo de ríos principales que sobre

Peter Trudgill (1986: 62) propone que, al igual que existen formas de interlengua -en el sentido de Selinker (1972) — en situaciones de contacto entre lenguas, también hay formas interdialectales, tales como formas intermediarias, hiperdialectalismos e hipercorrecciones, en situaciones de contacto entre dialectos con acomodación incompleta: «la etiqueta 'interdialecto' tiene el propósito de referirse a las situaciones en las que el contacto entre dos dialectos conduce al desarrollo de formas que en verdad no ocurrieron originariamente en ninguno de los dialectos». 
terreno dificultoso, y los haces de isoglosas coincidían a veces con las fronteras políticas o con las barreras físicas. Los mapas también indicaban la posible dirección tomada por un cambio linguístico o incluso podían arrojar luz sobre problemas tales como la edad aproximada de dos formas determinadas.

Como consecuencia de estas evidencias de los mapas, una escuela de lingüistas, la Neolingüística o Linguistica Spaziale ${ }^{5}$, basó sus fundamentos teóricos en cinco principios o normas espaciales que se utilizarían en la Lingüística Histórica, entre ellas: 1) si, de dos formas lingüísticas, una se encuentra en áreas aisladas y la otra en áreas más accesibles a la comunicación, entonces la primera es la más antigua; 2) si, de dos formas lingüísticas, una se encuentra en las áreas periféricas y la otra en las áreas centrales, entonces la primera es la más antigua; 3) si, de dos formas, una se utiliza en un área mucho mayor que la otra, entonces esa es la más antigua. Pero, como método de la Linguiística Histórica, se demostró que esta Lingüística Espacial era de dudosa utilidad para la serie de excepciones surgidas a estos principios, especialmente para el tercero, por razones estrictamente obvias; en el caso del segundo, si observamos la situación anteriormente descrita sobre la distinción / $\mathrm{u} /$ - / $/$ / en Gran Bretaña, los acentos de Escocia y los del sur de Inglaterra, que constituyen las áreas periféricas, tienen tal distinción en pares de palabras como put/putt o couldicud, mientras que los acentos de las regiones del norte y Midlands, que constituyen el área central, no la tienen, $y$, sin embargo, se sabe por otras fuentes -como descripciones y textos más antiguos- que son Escocia y el sur de Inglaterra las zonas innovadoras; una excepción al primer principio, por ejemplo, es el caso de la pronunciación de la secuencia wh-en palabras como what, which, when, etc. en Escocia, donde los dialectos rurales del noreste lo hacen con un sonido similar al labiodental fricativo/f/mientras que en el resto de áreas, incluso en las zonas industrializadas de las Lowlands escocesas y en el resto del mundo de habla inglesa, se pronuncia esa secuencia como $/ \mathrm{hw} /, \mathrm{y}$, sin embargo, se sabe que la realización como /f/ es posterior (cf. Trudgill 1975: 236).

Leyes fonéticas, como las de Grimm y Verner, que impulsaron notablemente las ideas neogramáticas, no tienen valor explicativo porque no son más que sumarios de lo que ocurrió en un área específica, o en una comunidad lingüística concreta, entre dos puntos del tiempo. Los cinco principios neolingüísticos, o normas espaciales, si bien tienen un indudable valor orientativo, no pueden considerarse como 'leyes' por su carencia de flexibilidad en un campo de estudio tan complejo como es la variación linguística. A diferencia de estas leyes generalizadoras de la Dialectología Tradicional, ahora es evidente que los cambios lingüísticos tienen lugar donde tienen lugar simplemente porque han tenido la oportunidad de triunfar allí más que en ninguna otra parte, y, una vez surgidos, se extienden a otras áreas si las condiciones les son favorables. Los

Cf. Mateo Bartoli (1925, 1945) y Giuliano Bonfante (1947). 
procesos implicados en el origen, desarrollo y difusión de las formas lingüísticas, como ya se ha indicado, eran por tanto mucho más complicados que el simple principio neogramático sobre el carácter universal, continuo y regular del cambio fonético y las posteriores generalizaciones de la Neolingüística: no sólo las características geográficas tales como las barreras físicas y la distancia están implicadas en la difusión de las formas lingüísticas, sino que también intervienen factores sociales que son igualmente efectivos: «... las barreras sociales son tan efectivas como las geográficas a la hora de interrumpir o retardar la difusión de las modas, ideas, valores y formas lingüísticas que se han originado en un grupo social específico, de una sección de la comunidad a otra» (Trudgill 1974a: 32); y donde hay mucha más movilidad y flujo es, indudablemente, en las comunidades urbanas, siendo la inmensa mayoría de la población actual lo geométricamente opuesto a los NORMs: ambulante, joven, urbana y femenina (mobile, younger, urban, y female) (Chambers \& Trudgill: 1980: 35). Además de las dimensiones espacial (geográfica) y temporal (diacrónica, concretamente) subrayadas por la Dialectología Tradicional Rural, se evidenció que era necesaria una especie de Dialectología Moderna Urbana que tomase en consideración una dimensión social y un punto de vista sincrónico.

\section{LA SOCIOLINGÜISTICA}

La Sociolingüística, «esa parte de la lingüística ocupada del estudio lenguaje como fenómeno social y cultural» (Trudgill 1983a: 32), y concretamente, dentro de ésta, la vertiente llamada Lingüistica Secular, Sociolingüística Laboviana, Sociolingüistica Cuantitativa, Sociolingüística Correlacional, o incluso Sociolingüística Auténtica, estuvo concebida en su origen en muy estrecha relación con la Dialectología Tradicional, en el momento de su redefinición y reformulación, reconociéndose entre ambas una conexión de evolución natural: además de la dimensión geográfica, los dialectólogos comenzaron a incorporar una dimensión social a sus descripciones lingüísticas. Después de la Segunda Guerra Mundial observaron que limitando los estudios dialectales a áreas rurales estaban ignorando el habla de la inmensa mayoría de la población, esto es, el habla de las grandes áreas urbanas, que no podían ser investigadas aplicando los métodos de la tradicional dialectología rural. De este modo, la Dialectología Urbana apareció combinando una función tanto linguiística como social y una dimensión sincrónica: «Aquellos dialectólogos urbanos que reconocieron que así era la realidad se vieron forzados, por tanto, a dilucidar cómo tenían que describir, de manera completa y precisa, el habla de grandes ciudades, y fue en respuesta a este problema por lo que la dialectología urbana, con el tiempo, llegó a ser sociolingüística (sociológica y lingüística, concretamente)» (Trudgill 1983a: 38). 
El mayor impulso a este movimiento en favor del análisis lingüístico que tuviese en cuenta una dimensión social y sincrónica y acometiese la supuesta inmanejabilidad de la variación vino dado, por tanto, por dialectólogos urbanos, quienes llevaron a cabo todo el proceso de redefinición y reformulación de la Dialectología Tradicional, especialmente el americano William Labov. Asumiendo que «si no todas, la mayoría de las comunidades de habla son más o menos heterogéneas lingüística y socialmente» y que la variación lingüística está socialmente condicionada, Labov «aplicó una metodología sociológica a una comunidad lingüística heterogénea con resultados que tuvieron diversas e importantes implicaciones teóricas para la teoría lingüística» (Trudgill 1974a: pp. 2-3). Así, partiendo de la base de que la variación en la lengua está socialmente condicionada y haciendo uso de los métodos y descubrimientos de las ciencias sociales - como la Sociología y la Antropología- y de las modernas innovaciones técnicas - tales como las grabadoras de alta fidelidad portátiles-, el principal objetivo del sociolingüista es obtener una descripción completa y representativa de la variedad de habla local de los habitantes de una comunidad urbana. Para ello, seleccionan a los informantes aleatoriamente, normalmente para una entrevista grabada, y correlacionan los datos obtenidos -unos rasgos distintivos predeterminados (las variables lingüisticas)-, con parámetros sociales, tales como la edad, el sexo, la clase social, la raza, la afiliación religiosa, etc. -también Ilamados variables no lingüísticas o sociales; y aquellas variables lingüísticas que se correlacionen significativamente con variables sociales son llamadas variables sociolingüísticas, esto es, formas alternativas de decir lo mismo, si bien socialmente significativas. Además, intentan obtener el discurso libre del informante, el habla vernácula, lo más natural posible (teniendo en cuenta la paradoja del observador de Labov) puesto que sus estudios se ocupan no sólo de la variación social entre los indiviđuos de diferente posición social sino también de la variación estilística dentro del habla de un solo informante, y así someten a éste a varios contextos: informal 'causal', formal, 'cuidadoso' de lectura, etc. Otro objetivo no menos importante es el de registrar la competencia comunicativa del informante en comparación con su actuación; esto es, la Sociolingülstica Laboviana quiere averiguar el conocimiento que el hablante particular tiene acerca del tipo de lenguaje más apropiado para las diferentes situaciones sociales en las que se pueda encontrar y su habilidad para cambiar fácilmente de un estilo a otro, y no sólo su mera actuación. Este impulso se ha traducido en numerosos estudios llevados a cabo en diferentes comunidades de habla: los trabajos realizados en Nueva York por William Labov (1966), Detroit por Roger Shuy, Walt Wolfram \& Ralph Rasold (1967), Montreal por Gillian Sankoff \& Henrietta Cedergren (1971), Norwich por Peter Trudgill (1971, aunque publicado en 1974a), Belfast por Lesley Milroy \& James Milroy (1978), Reading por Jenny Cheshire (1978), Glasgow por Ronald Macaulay (1977 y 1978), Edimburgo por Euan Reid (1976 y 1978), Liverpool 
por G.O. Knowles (1974 y 1978), San Juan por Humberto López Morales (1983), y Sydney por B. Horvath (1985) son los más conocidos a nivel internacional.

Del mismo modo que hay dialectos regionales y continuos dialectales geográficos, también hay dialectos sociales, o sociolectos, y continuos dialectales, sociales, en los que los dialectos sociales no son entidades discretas sino gradualmente variables: «... la relación existente entre acento y clase social es una cuestión de más-o-menos más que de todo-o-nada. No es que unos grupos empleen una variante y otros otra; más bien es que todos los grupos emplean las dos variantes, aunque en proporciones diferentes» (Chambers \& Trudgill 1980: 68). Estos postulados consiguió demostrarlos William Labov (1966) en su estudio llevado a cabo en una inmensa urbe como la de Nueva York, donde observó que el uso de las variantes lingüísticas está muy relacionado con la clase social: si una variable lingüística revela estratificación de clases, ciertas variantes serán utilizadas más frecuentemente por las clases de estatus más alto, menos frecuentemente por las clases intermedias, todavía mucho menos frecuentemente por las clases de estatus más bajo, y viceversa, siendo la frecuencia la que indica su estatus social aproximado. Pero en estos estudios también se ha demostrado que la variabilidad no es sólo una cuestión de diferencias existentes entre las clases sociales y la pronunciación, sino también de diferentes pronunciaciones dentro de las mismas clases sociales según las situaciones. Esto es, los cambios en la pronunciación también pueden ser hechos, consciente o inconscientemente, por los hablantes según perciban la situación (formal-informal) en que se encuentran: el juicio del hablante sobre la formalidad depende de factores tales como el relativo estatus de la persona con la que habla, el nivel de confianza entre uno y otro, el tema tratado, el propósito y el lugar donde ocurre la interacción (Hughes \& Trudgill 1979: 4). En su trabajo de Norwich, Peter Trudgill (1974a) dividió el continuum de estilos de habla en cuatro, oscilando del menos al más formal: estilo casual (EC), estilo formal (EF), estilo lectura de texto (ELT), y estilo lectura de palabra (ELP). La correlación del contexto social (variables estilísticas) con la clase social y la variable linguística (ng) ofreció los siguientes resultados:

\begin{tabular}{|l|cccc|}
\hline \multicolumn{5}{|c|}{ Indice (ng) por Clase y Estilo } \\
\hline & \multicolumn{4}{|c|}{ Estilo } \\
\cline { 2 - 5 } Clase & ELP & ELT & EF & EC \\
\hline & 000 & 000 & 003 & 028 \\
CMM & 000 & 010 & 015 & 042 \\
CMB & 005 & 015 & 074 & 087 \\
COA & 023 & 044 & 088 & 095 \\
COM & 029 & 066 & 098 & 100 \\
COB & & & & \\
\hline
\end{tabular}




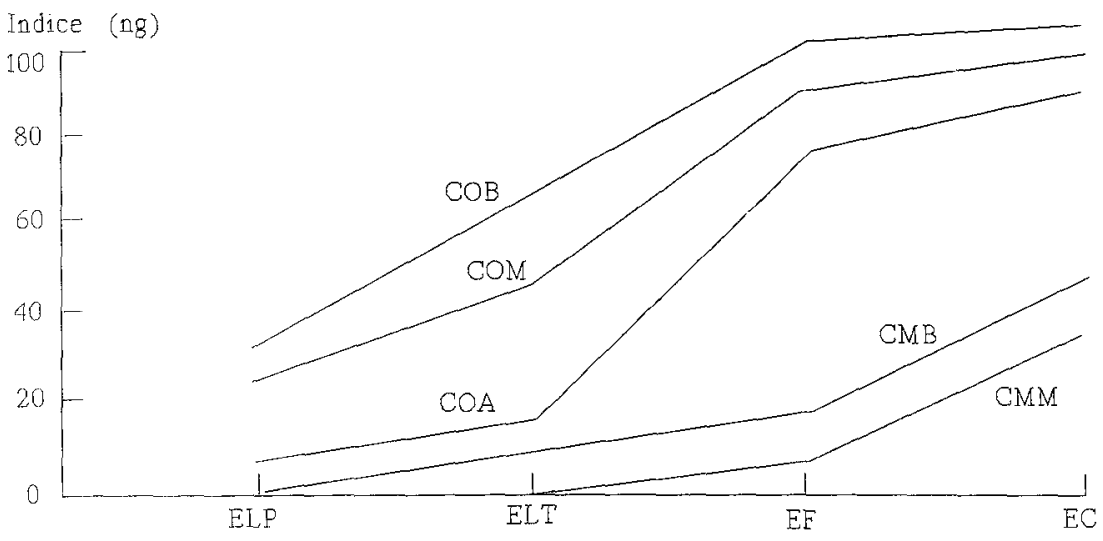

ESTILO

Fuente: Peter Trudgill (1974a: 92)

Los veinte resultados visualizados en la tabla anterior y en el gráfico son ciertamente reveladores ya que ascienden de forma consistente desde el estilo lectura de texto (ELT) hasta el estilo casual (EC), desde la clase media-media $(\mathrm{CMM})$ a la clase obrera-baja (COB), y oscilan de 0\% —uso consistente de la variante prestigiosa [n]- a $100 \%$ - uso consistente de la variante [n]. Esto indica que, aunque los diferentes grupos de clases sociales tienen distintos niveles de uso de la (ng), su evaluación de las dos variantes es exactamente la misma: los hablantes de todas las clases tienden a modificar su pronunciación exactamente en la misma dirección, elevando el porcentaje de uso de la forma [ $\eta]$ del RP de estatus social prestigioso, conforme aumenta el nivel de formalidad del contexto estilístico, y viceversa. Esto conduce a un contraste interesante como es el hecho de que en los estilos formales el habla de la clase baja se aproxima al habla informal de la clase alta: la CMM en su estilo casual emplea, por término medio, la misma cantidad de formas no RP que la $\mathrm{COB}$ en sus 
estilos más formales. Otro fenómeno interesante es el hecho de que la COA y la $\mathrm{COB}$ se distinguen una de la otra principalmente por la mucho mayor conciencia que los hablantes de COA tienen de la significación social de las variables linguísticas, como consecuencia de la naturaleza 'fronteriza' de la posición de su clase social; esta naturaleza 'fronteriza' de los hablantes de COA conduce a una inseguridad lingüística en su habla, que aquí se refleja con su gran cantidad de variación estilística para la variable (ng), de 005 a 087 en la tabla y una línea con la pendiente más pronunciada en el gráfico. En este mismo sentido, William Labov (1966) descubrió que había situaciones en las que los hablantes de CMB prestaban considerable atención a su habla, exageraban los casos y sobrepasaban incluso a los de las clases más elevadas en su uso de un determinado rasgo prestigioso, como es la / $\mathbf{r}$ / postvocalica en la ciudad de Nueva York tal y como el siguiente gráfico nos muestra:

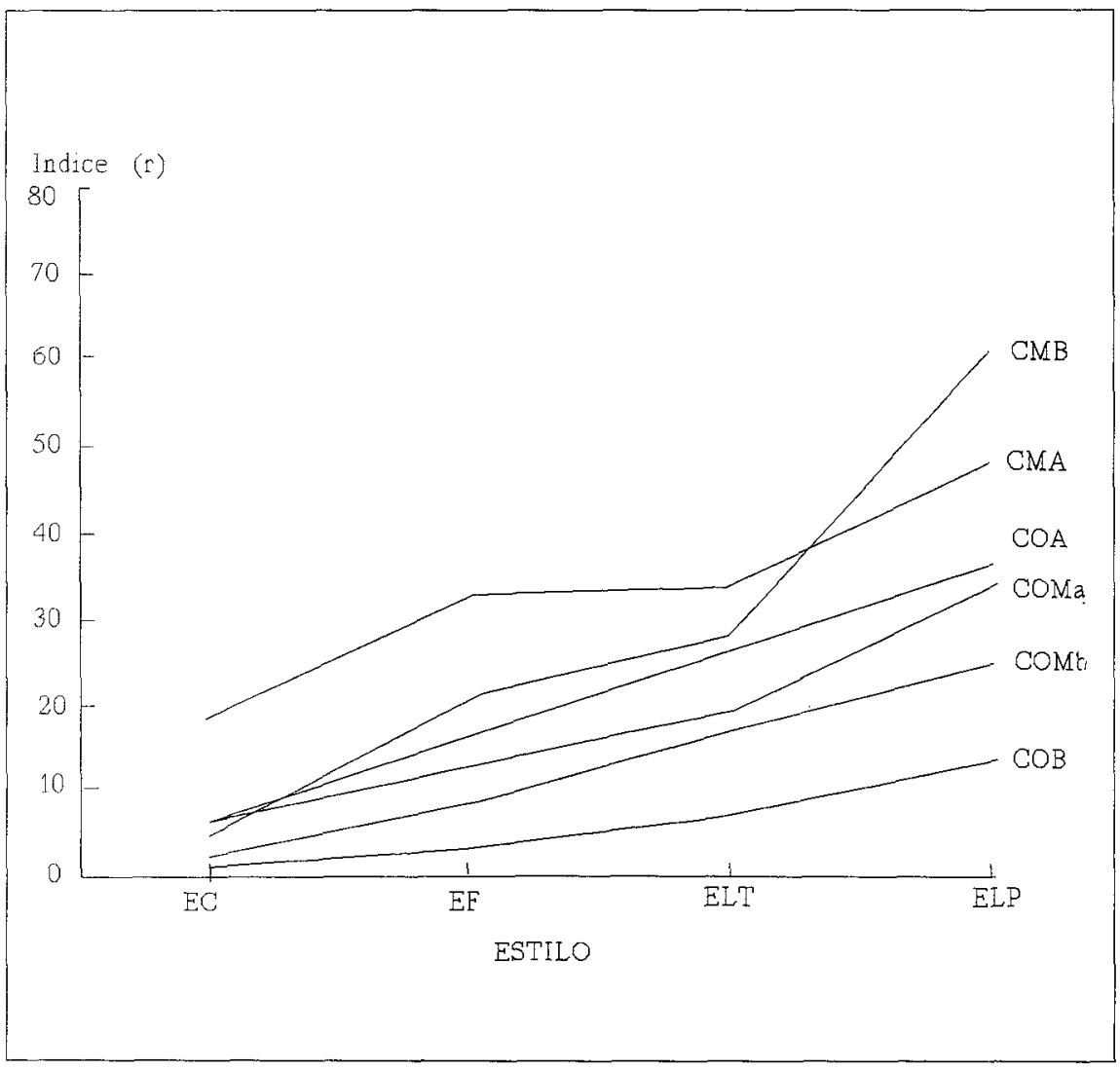

Fuente: William Labov (1966) 
Labov consideró este fenómeno como un caso de hipercorrección, y lo explicó en términos de inseguridad lingüística de la CMB: los hablantes de clase media baja no están tan seguros socialmente como los de la CMA y no están lo suficientemente distanciados de la clase obrera como para estar seguros de que no los van a identificar con ellos; por tanto, en esas situaciones en las que los hablantes de CMB controlan muy estrechamente su habla realizan grandes esfuerzos para mostrar su estatus social haciendo uso, e inconscientemente excediéndose, de rasgos lingüísticos de prestigio.

Pero no todas las variables lingüísticas siguen este modelo de variación social y estilística que la (ng) ofreció; esto es, no todas las variables que estaban sujetas a diferenciación por clase social exhibían también variación estilística. La variable (a:), por ejemplo, cuando se correlacionaba con la clase social y el estilo sufría muy poca o prácticamente ninguna variación estilística:

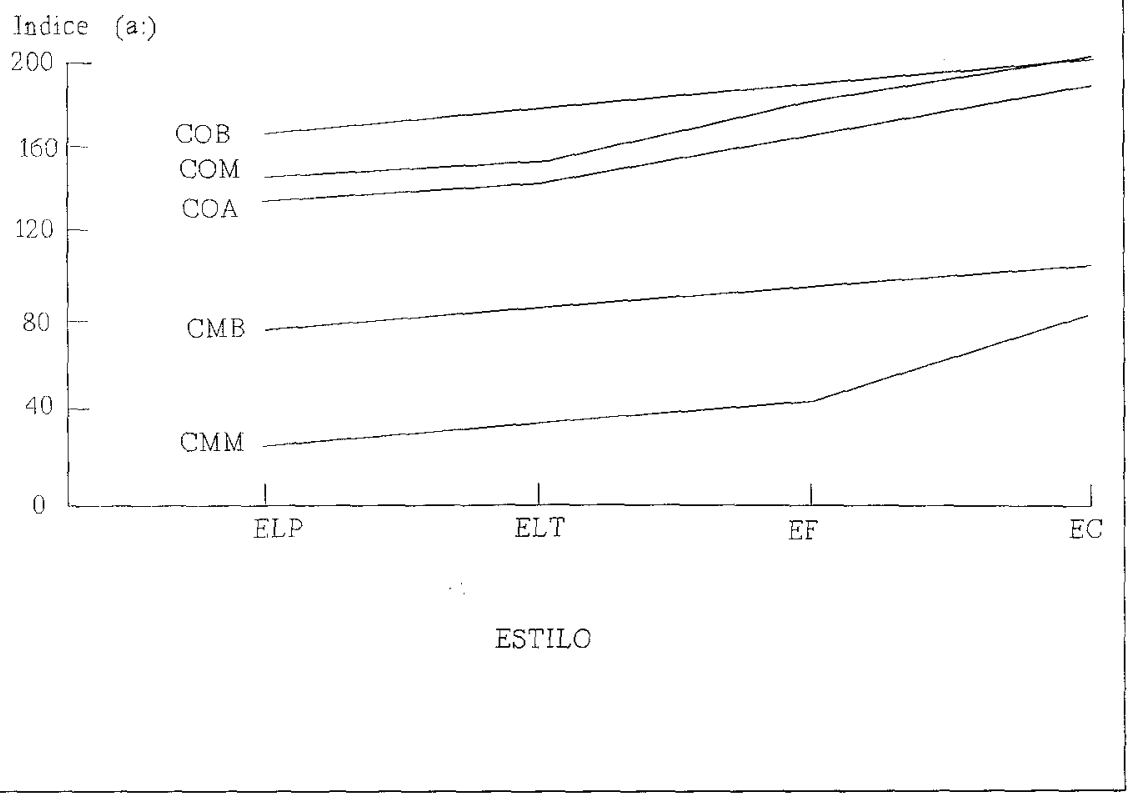

Fuente: Peter Trudgill (1974a: 98) 
Por tanto, si en unas variables la variación social es amplia pero hay poca o ninguna estilística, por el contrario, en otras los datos muestran escasa diferencia entre las clases, pero considerable variación estilística probablemente, según Trudgill (1974a: 103), porque o (i) están sufriendo un cambio lingüístico; o (ii) están sujetas a presiones correctivas manifiestas; o (iii) están implicadas en contrastes fonológicos superficiales; o (iv) son considerablemente diferentes al acento equivalente de prestigio (en el caso de aquellos hablantes que tengan algún contacto con éste).

Tomando al sexo del hablante como parámetro social en los estudios sociolinguísticos también se ha demostrado que las diferencias lingüísticas se correlacionan muy estrecha y significativamente. La variable (ng) también ofreció los siguientes resultados en Norwich:

\begin{tabular}{|c|c|c|c|c|c|}
\hline \multicolumn{6}{|c|}{ Indice (ng) por Clase y Estilo } \\
\hline \multirow{2}{*}{\multicolumn{2}{|c|}{ Clase }} & \multicolumn{4}{|c|}{ Estilo } \\
\hline & & ELP & ELT & $\mathrm{EF}$ & $\mathrm{EC}$ \\
\hline \multirow[t]{2}{*}{ CMM } & $\mathrm{h}$ & 000 & 000 & 004 & 031 \\
\hline & m & 000 & 000 & 000 & 000 \\
\hline \multirow[t]{2}{*}{$\mathrm{CMB}$} & $\mathrm{h}$ & 000 & 020 & 027 & 017 \\
\hline & m & 000 & 000 & 003 & 067 \\
\hline \multirow[t]{2}{*}{$\mathrm{COA}$} & $\mathrm{h}$ & 000 & 018 & 081 & 095 \\
\hline & $\mathbf{m}$ & 011 & 013 & 068 & 077 \\
\hline \multirow[t]{2}{*}{$\mathrm{COM}$} & $\mathrm{h}$ & 024 & 043 & 091 & 097 \\
\hline & m & 020 & 046 & 081 & 088 \\
\hline \multirow[t]{2}{*}{$\mathrm{COB}$} & $\mathrm{h}$ & 066 & 100 & 100 & 100 \\
\hline & $\mathbf{m}$ & 017 & 054 & 097 & 100 \\
\hline
\end{tabular}

Fuente: Peter Trudgill (1974a: 94)

En diecisiete casos de veinte, los resultados de los varones (h) son mayores o iguales que los correspondientes a las mujeres $(\mathrm{m})$ : el uso de la variante [n] no RP es mucho más frecuente en el habla de los hablantes varones y en el de la clase obrera en general. Este mismo modelo se ha obtenido en muchos otros estudios llevados a cabo por muchos otros investigadores y con muchas variables distintas ( $c f$. Suzanne Romaine 1978, Gillian Sankoff \& Henrietta Cedergren 1971 , etc.), coincidiendo todos ellos en el hecho de que «en iguales condiciones, las mujeres tienden, por término medio, a emplear más variantes de mayor estatus social que los hombres» (Chambers \& Trudgill 1980: 72). 
El uso del factor edad como parámetro social ha demostrado que la diferenciación ontogenética también es posible en el lenguaje si correlacionamos variables linguísticas con grupos de edad, además de con la clase social y los estilos. La variable (ng) de Norwich, con la variante prestigiosa [ $\eta$ ] del RP y la variante no prestigiosa [n], también sufría la influencia del factor edad, ofreciendo los siguientes resultados:

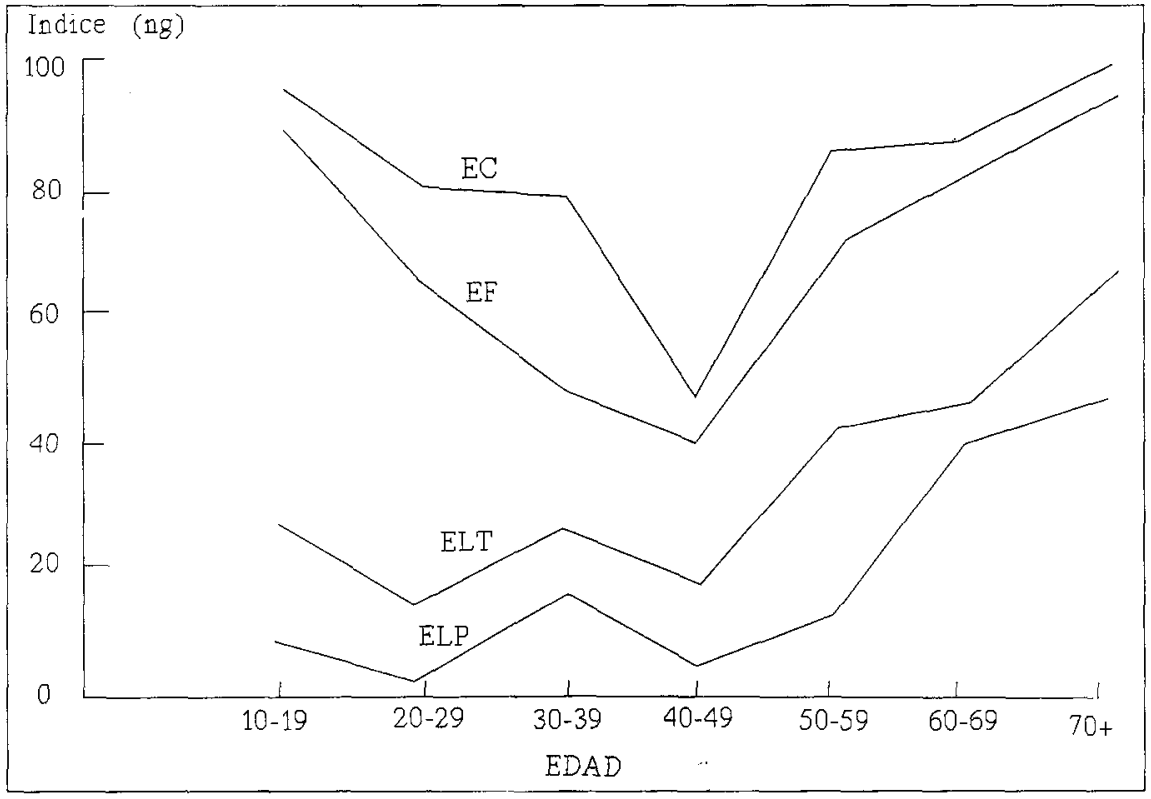

Fuente: Chambers \& Trudgill (1980:91)

El resultado de esta gráfica muestra un modelo curvilíneo en el que los hablantes más jóvenes y los más viejos tienen los índices de uso más elevados de la variante no RP [n], mientras que los hablantes de edad media tienen los más bajos. Esto se puede explicar suponiendo que «para los hablantes más jóvenes las presiones sociales más importantes provienen de la 'pandilla', y que linguiísticamente están más fuertemente influenciados por sus amigos que por nadie más. La influencia de la lengua estándar es relativamente débil. Luego, conforme se hacen mayores y empiezan a trabajar, se mueven en unas redes sociales más amplias y menos cohesivas [...] y están más influenciados por los valores sociales convencionales y, quizás, por la necesidad de impresionar, triunfar, y progresar social y económicamente. Consiguientemente, 
linguiísticamente también están más influenciados por la lengua estándar. Por el contrario, para la gente mayor, jubilada, las presiones sociales vuelven a ser menores, el triunfo ya se ha logrado (o no, según sea el caso), y las redes sociales pueden volver a ser más estrechas» (Chambers \& Trudgill 1980: 92).

Los estudios sociolinguísticos de corte laboviano también han demostrado que «en muchos casos, la lengua puede ser una importante o incluso esencial manifestación de la militancia en grupo étnico» (Trudgill 1983a: 53), y que la diferenciación de grupos étnicos en una comunidad mixta puede ser un tipo determinado de diferenciación social que adicionalmente implica diferenciación lingüística. Así es el caso, por ejemplo, de las diferencias existentes entre el habla de los americanos negros y blancos: Walt Wolfram (1971) llevó a cabo un estudio en el área del delta del Mississippi en los Estados Unidos sobre el uso de la cópula be en el habla de los hablantes negros y blancos y obtuvo los siguientes resultados:

\begin{tabular}{|c|cc|cc|}
\hline \multirow{2}{*}{ (be) } & \multicolumn{2}{|c|}{ is } & \multicolumn{2}{c|}{ are } \\
\cline { 2 - 5 } & Negros & Blancos & Negros & Blancos \\
\hline Forma Completa & 054 & 038 & 017 & 034 \\
Forma Contracta & 018 & 060 & 006 & 045 \\
Forma Omitida & 028 & 002 & 077 & 021 \\
\hline \multicolumn{1}{|c|}{ Total } & 100 & 100 & 100 & 100 \\
\hline
\end{tabular}

Las tres formas lingüísticas son empleadas por ambos grupos étnicos, hablantes blancos y negros, pero con distintos niveles de frecuencia: «los hablantes negros, por término medio, muestran una tendencia mayor por la omisión que los blancos, quienes, por otro lado, emplean mucho más la contracción» (Chambers \& Trudgill 1980: 75).

Pero las diferencias de grupos étnicos en el lenguaje pueden considerarse como un ejemplo concreto del papel desempeñado por las redes sociales en la conducta linguística. Diferentes estudios han demostrado que la gente está influenciada lingüísticamente por los miembros de los sistemas de redes sociales a los que pertenecen, e incluso dentro del mismo grupo social puede haber diferencias lingüísticas muy estrechamente relacionadas con la naturaleza central/marginal de sus miembros. Lesley Milroy (1980) investigó el inglés hablado en Belfast, Irlanda del Norte, no por medio de los procedimientos de Labov y Trudgill (muestreo aleatorio), sino entablando contacto con un miembro nuclear de cada comunidad de Belfast y progresando con más contactos a través de la primera persona conocida (la técnica del 'amigo de un amigo'). Las áreas investigadas fueron tres comunidades de clase obrera de los barrios céntricos de la ciudad, aunque socialmente eran muy diferentes: The Hammer, un área 
protestante del Belfast Oeste que había perdido su tradicional industria de lino dejando a los varones sin empleo o teniendo que salir fuera del área de trabajo, y consiguientemente con sus redes sociales haciéndose menos densas y más desintegradas; Clonard, un área católica también situada en el Belfast Oeste y atravesando la misma situación que The Hammer, aunque su población femenina joven forma una red relativamente homogénea por el hecho de tener un empleo común; y Ballymacarret, un área protestante del Belfast Este que todavía conserva su tradicional industria local (astilleros) y sus vínculos de redes sociales. Estos factores y las diferencias sociales tuvieron algunas consecuencias en la naturaleza del sistema de redes sociales de las comunidades de Belfast, tales como la variable (æ) con la variante [a] empleada por la clase media y una variante que está sufriendo algunos procesos en su articulación (velarización, palatalización, y labialización) y que es utilizada por la clase obrera. La correlación de estas variables lingüísticas con parámetros sociales y con el contexto estilístico da los siguientes resultados:

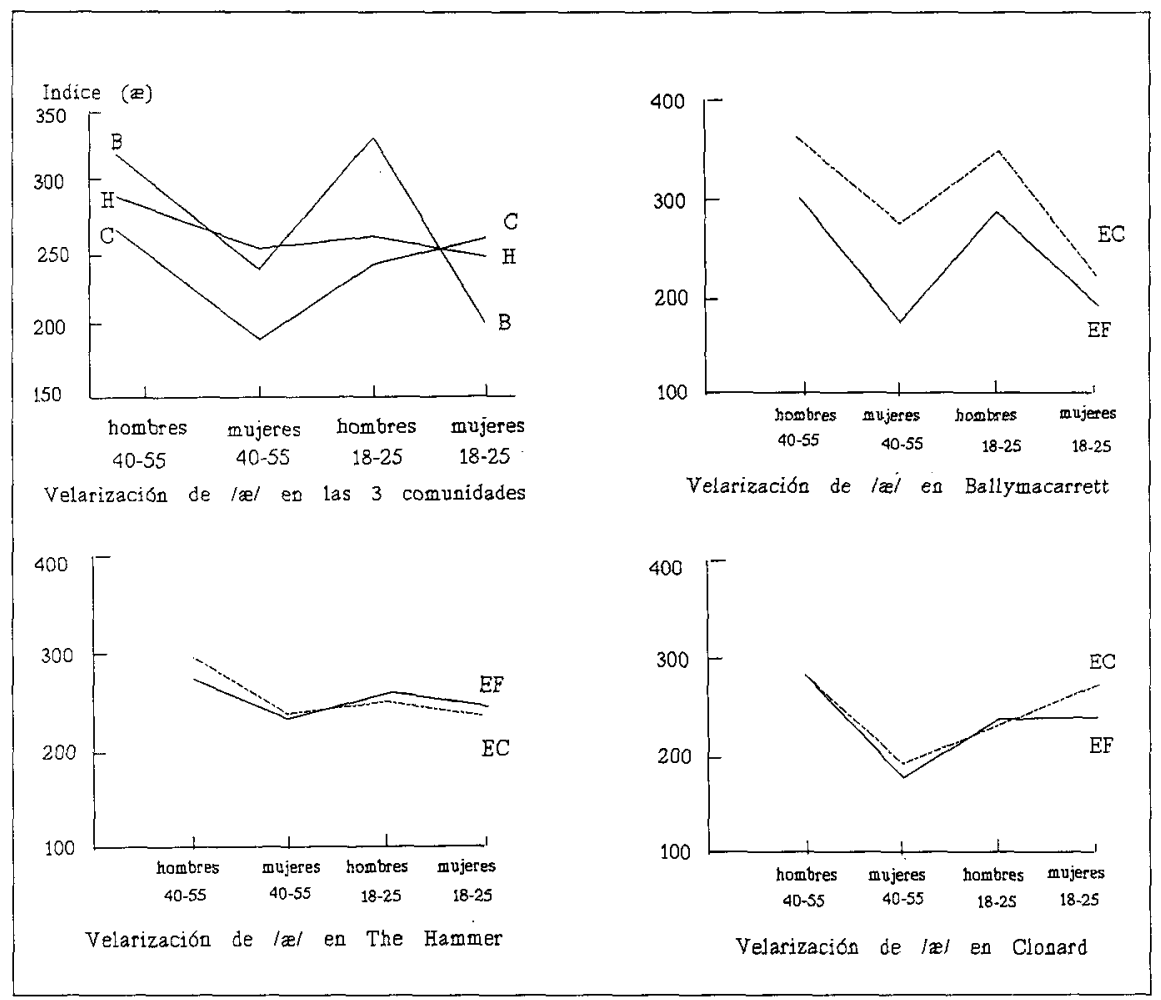

Fuente: Chambers \& Trudgill (1980: 78) 
Mientras que la población femenina joven de Ballymacarret emplea rasgos más estándares y más prestigiosos, en Clonard ocurre exactamente todo lo contrario: «... en el área de Ballymacarret, socialmente estable, hay una diferenciación de sexo y estilo clara y regular. En las dos zonas menos estables hay mucha menos variación estilística, y a menudo es irregular. Y la variación por sexo es menos significativa, concretamente en The Hammer. Sin embargo se puede observar que para la gente joven de Clonard, la diferenciación de sexo ocurre de forma totalmente opuesta. Se puede observar también que la población femenina más joven de Clonard tiene unos índices más elevados que la de Ballymacarret, aunque para los varones es el caso contrario». Esto significa que «el estadio más avanzado de este cambio lingüístico se encuentra en el área estable de Ballymacarret, con las zonas socialmente menos cohesivas a continuación —con la importante excepción de la población femenina joven de Clonard- que, nuevamente como consecuencia de sus relaciones de redes sociales densas, también está en un estadio relativamente avanzado. El grado de 'velarización' de esta vocal refleja, hasta cierto punto, el grado de cohesión social» (Chambers \& Trudgill 1980: 79).

Pero el hecho de que la lengua se correlacione de manera significativa con los rasgos distintivos sociales no implica en absoluto que los estudios sociolingüísticos sean simplemente trabajos correlacionales y descriptivos de poco interés teórico, sino que sus objetivos son crear una teoría sociolingüística de base empírica, científica, que en última instancia aspira a «saber más sobre el lenguaje, e investigar temas tales como los mecanismos del cambio linguístico; la naturaleza de la variabilidad lingüística; y la estructura de los sistemas lingüísticos» (Trudgill 1978: 11). Todos estos modelos de diferenciación social han evidenciado que también pueden encontrarse en la estructura sociolingüística de un sistema e incluso pueden ser indicativos de un cambio lingüístico en proceso. Esto es, en el desarrollo de cualquier cambio lingüístico, o innovación, hay algunos elementos de la sociedad — clase social, edad, sexo, grupo étnico, etc., además de la zona geográfica- que están a la vanguardia de una innovación determinada. En las innovaciones basadas en la clase social, son la COA y la CMB las que normalmente tienen un habla más marcadamente divergente de las normas de los grupos sociales situados por debajo de ellos en la escala, por su tendencia a la continua movilidad social. En las innovaciones basadas en la edad, es la población de hablantes más jóvenes la que normalmente muestra en su habla los rasgos innovadores, del mismo modo que la gente mayor muestra unas formas más conservadoras. Muy frecuentemente las innovaciones también están basadas en el sexo, siendo la mujer ese hablante que es más consciente de un cambio linguístico si éste tiene lugar en la dirección de la variedad de prestigio.

El carácter arbitrario y subjetivo de las actitudes sociales frente al prestigio de las variedades linguísticas ha sido igualmente causa de cambios lingüísticos, 
como es el caso del fenómeno del rotacismo ya indicado más arriba al tratar los estudios dialectológicos. En Inglaterra, los acentos no róticos tienen más prestigio y son considerados como más 'correctos' que los róticos, los cuales son estimados como rurales, incultos, o ambas cosas a la vez; esta pronunciación rótica está por tanto socialmente estigmatizada en Inglaterra, y cuanto más alta sea la escala social de un hablante menos probabilidad de uso de / $\mathrm{r}$ / postvocálica hay. Sin embargo, en algunas zonas de los Estados Unidos, Nueva York y otras ciudades, la situación es precisamente la contraria, siendo los acentos con $/ \mathrm{r} /$ postrocálica los que tienen más prestigio y son considerados más 'correctos' que aquéllos que carecen de este rasgo rótico. Este contraste en las actitudes frente a las formas de la lengua demuestra algo muy importante para los psicólogos sociales, y los sociolingüistas en general, que «la sociedad evalúa las diferentes variedades lingüísticas de distinta forma». Con el estudio de a estas actitudes subjetivas frente a las formas de lengua, también podemos encontrar explicaciones que a menudo son útiles para el estudio del cambio lingüístico, puesto que hay indicios suficientes para sugerir que las actitudes subjetivas son la causa antes que el efecto de muchos de estos cambios, los cuales pueden tener lugar no sólo en la dirección de una forma prestigiosa, como es el caso de Nueva York, sino incluso en la opuesta, como ocurre en Martha's Vineyard. Si actualmente en la ciudad de Nueva York el rotacismo es un rasgo de prestigio, se sabe, sin embargo, que había sido una región que pronunciaba la $<r>$ en el siglo XVIII, pero pasó a omitirse completamente desde el XIX hasta la Segunda Guerra Mundial. Fue desde la guerra cuando la pronunciación de la $\langle r\rangle$ de nuevo llegó a ser prestigiosa y el cambio en la frecuencia de uso de la $/ r /$ postvocálica aumentó en el habla de la clase media alta, probablemente como consecuencia de la afluencia a la ciudad de hablantes procedentes de áreas donde la / $/$ postvocálica era un rasgo estándar o de prestigio y también probablemente como consecuencia de un cambio en las actitudes subjetivas de los neoyorquinos frente a este tipo de pronunciación - de una clara indiferencia a un deseo general por adoptar tal pronunciación. Este hecho pudo cuantificarlo William Labov en una investigación llevada a cabo sobre las actitudes subjetivas y evaluación por parte de los informantes de la pronunciación de la $\langle\mathrm{r}\rangle$ : detectó un brusco aumento en la evaluación favorable de la pronunciación de la $<r>$ entre los hablantes menores de cuarenta años, siendo mayor el uso de la /r/ postvocálica cuanto más jóvenes son los hablantes:

Un cambio lingüístico sufrido en la dirección no precisamente de un modelo prestigioso sino en el opuesto es el caso de Martha's Vineyard, una isla a tres millas de la costa de Massachussets, en Nueva Inglaterra. Antiguamente Martha's Vineyard estaba aislada, teniendo una pequeña población permanente de alrededor de 6.000 habitantes, pero comenzó a sufrir un aumento del número de turistas durante los meses de verano. Este creciente número de visitantes provocó cambios sociales sorprendentes que también tuvieron consecuencias 


\begin{tabular}{|c|c|c|}
\hline \multicolumn{3}{|c|}{$\begin{array}{c}\text { Actitudes frente a y uso de la /r/ postvocálica: } \\
\text { clase media alta en la ciudad de Nueva York }\end{array}$} \\
\hline Edad & $\%$ informantes r-positiva & $\% / r /$ usada \\
\hline $8-19$ & 100 & 48 \\
$20-39$ & 100 & 34 \\
$40+$ & 62 & 9 \\
\hline
\end{tabular}

Fuente: Trudgill (1983a: 22)

lingüísticas en la isla, y que fueron estudiados por William Labov (1966). Labov centró su atención en la manera en que los nativos de esta isla pronunciaban los diptongos en los dos grupos de palabras out, house y trout, por un lado, y while, pie y night, por otro. De hecho, había dos pronunciaciones diferentes de

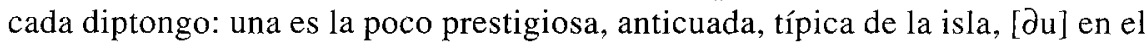

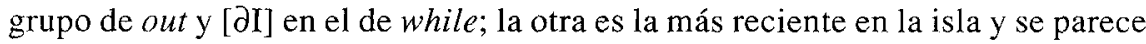
mucho más a los diptongos de RP y a algunos acentos prestigiosos del continente americano, [au] en out y [ai] en while. En su estudio, Labov observó que el uso de la forma 'anticuada' iba en aumento, haciéndola más exagerada y siendo cada vez más frecuente en el habla de un mayor número de hablantes. La explicación encontrada a este cambio linguístico está muy relacionada con las actitudes subjetivas de los hablantes: los residentes han exagerado la pronunciación 'anticuada' para mostrar sus diferencias frente a la población de verano: «Los nativos de la isla se han sentido agraviados por la invasión de forasteros y el cambio y la explotación económica que ello conlleva. Por ello, aquella gente que más se identifica con el modo de vida de la isla ha comenzado a exagerar la pronunciación típica del lugar, con el propósito de indicar su diferente identidad social y cultural, y para subrayar su creencia en los viejos valores. Esto hace que la pronunciación 'anticuada' sea, de hecho, la más en boga entre ciertos sectores de la comunidad más joven» (Trudgill 1983a: 23).

Si los casos de Nueva York y Martha's Vineyard investigados por Labov demuestran que las actitudes frente a la lengua pueden ser una poderosa fuerza en la difusión de cambios lingüísticos, también es cierto que la acomodación lingüística entre los hablantes ayuda a originar modificaciones lingüísticas en la interacción conversacional, e incluso también, a la difusión del cambio lingüístico. Utilizando datos linguiísticos, el psicólogo social del lenguaje Howard Giles desarrolló lo que se conoce como teoría de la acomodación, que se centra en el habla e intenta explicar por qué los hablantes modifican su lengua en presencia de otros del modo y grado en que lo hacen: «Esto, en pocas palabras, trata de 
explicar los ajustes temporales o a largo plazo en la pronunciación y en otros aspectos de la conducta lingüística en términos de mecanismo para aproximar la lengua de uno a la de los interlocutores, si se les considera socialmente atractivos y/o demuestra buena voluntad hacia ellos. A menudo consiste en reducir la frecuencia de formas lingüísticas socialmente estigmatizadas en presencia de hablantes de variedades de mayor prestigio. La teoría también prevé el efecto opuesto: el distanciamiento de la lengua de uno con respecto a la de los hablantes de los que uno quiere disociarse, o con el propósito de afirmar la identidad propia» (Trudgill 1983b: 143). El primer caso se relacionaría con lo que Howard Giles llamó proceso de convergencia acentual, «si el emisor en una situación dual desea conseguir la aprobación social del receptor, entonces puede adaptar sus modelos acentuales en la dirección de los de esta persona, esto es, reducir las diferencias de pronunciación» (Giles 1973). El segundo caso, el proceso opuesto, cuando los hablantes desean disociarse mutuamente o mostrar desaprobación de otros, estaría relacionado con la divergencia acentual; de esta manera, el uso de un estilo formal en una situación informal, por ejemplo, puede utilizarse como broma o para indicar desaprobación o distancia social. Pero la teoría de la acomodación no sólo se ocupa de ajustes de acentos de prestigio alto-bajo sino también de acentos geográficamente diferentes: según Trudgill (1986), la teoría de Howard Giles es una base útil para el entendimiento de la convergencia/divergencia lingüística que tiene lugar cuando los hablantes de dialectos diferentes interaccionan y para el posible proceso de difusión de un cambio lingüístico. Así, teniendo en cuenta tanto la acomodación a corto plazo entre los miembros de la misma región o comunidad de habla como la acomodación a largo plazo entre los miembros de diferentes regiones o comunidades de habla y empleando un análisis lingüístico cuantitativo como herramienta de investigación, Trudgill explora una serie de preguntas sin contestar sobre este proceso, tales como a qué rasgos lingüísticos le afecta, en qué orden, y por qué, con el fin último de detectar regularidades en las situaciones de acomodación, poder hacer generalizaciones teóricas y, por tanto, poder pronosticar el cambio lingüístico y la difusión en las situaciones de contacto y mezcla de dialectos ${ }^{6}$.

6. Un concepto clave es la relativa prominencia de un rasgo dialectal, que es una medida tanto de su conocimiento como de su distintividad con respecto a los hablantes de otros dialectos y su disposición para variar o acomodarse a éstos: «la acomodación tiene lugar realmente con la modificación de aquellos aspectos de la fonología segmental que son prominentes en el acento al que hay que acomodarse» (Trudgill 1986: 20). 


\section{LA GEOLINGÜISTICA}

Jack Chambers y Peter Trudgill (1980: Cap. 12) hablan de la Geolingüistica como la confluencia de tres áreas: la geografía lingüística (Dialectología), la dialectología urbana (Lingüística Secular) y la geografía humana (Geografía). Peter Trudgill (1983b: Cap. 3) sostiene que los dialectólogos «no deberían contentarse simplemente con describir la distribución geográfica de los rasgos lingüísticos distintivos sino que también deberían ocuparse de explicar esta distribución». Esto es, diciendo exactamente por qué y cómo los rasgos lingüísticos distintivos en proceso de cambio linguiístico se difunden de un lugar o grupo social a otro, podríamos entender con mayor precisión los mecanismos sociolingüísticos que subyacen a la distribución geográfica de las innovaciones lingüísticas. Para ello los dialectólogos tienen que emplear determinadas técnicas y conceptos teóricos desarrollados por los geógrafos sociales. Los mapas dialectales deberían ser mejorados considerablemente mediante el uso de técnicas cartográficas de la Geografía $a^{7}$ : se divide el terreno de manera uniforme en una serie de áreas, casillas, y los investigadores tienen que calcular el porcentaje de uso de un determinado rasgo distintivo lingüístico en cada casilla, en determinados momentos del tiempo, del mismo modo que William Labov calculó los porcentajes de las casillas de diferentes clases sociales; esto es, tienen que mostrar no sólo la posición geográfica de un fenómeno específico sino también, por ejemplo, su densidad y distribución social. Conceptos teóricos desarrollados por los geógrafos sociales tales como los modelos de difusión, el efecto de vecindad y el modelo de gravedad pueden dar cuenta de la relativa densidad de población de áreas adyacentes, las redes de conexión entre un área determinada y grandes centros de población, la posición geográfica de una innovación, el grupo social innovador, el relativo prestigio de determinadas variedades, la distancia lingüística entre las variedades, y los sistemas lingüísticos mismos como factor de resistencia con la posible semejanza lingüística pre-existente entre ambos. La aplicación de estas técnicas en los mapas y el conocimiento por parte de los dialectólogos de estos conceptos teóricos procedentes de la Geografía podrían hacer que la Lingǘstica averiguase la difusión geográfica de rasgos distintivos lingüísticos, o lo que es lo mismo, por qué las innovaciones lingüísticas surgen y se difunden a un núcleo $\mathrm{A}$ desde un núcleo $\mathrm{B}$ y no desde un núcleo $\mathrm{C}$. Así, adaptando fórmulas empleadas por los geógrafos ( $c f$. Olsson 1965 y Haggett 1965), Trudgill (1974b) desarrolló una ecuación para cuantificar modelos de gravedad en la difusión de los cambios linguísticos y calcular el grado de

7 Peter Trudgill se refiere a las técnicas utilizadas en mapas por el geógrafo sueco $T$. Hägerstrand, quien sostenía que «cuando estudiamos cambios, no podemos trazar líneas fronterizas y observar sus desplazamientos. Más bien, debemos averiguar la difusión espacial de las proporciones -the spatial diffusion of ratios» (Hägerstrand 1952) 
influencia de un centro urbano $x$ sobre otro $y$, teniendo en cuenta factores decisivos en el proceso como son la distancia entre éstos, las poblaciones respectivas (o número de habitantes) y la posible semejanza lingüistica pre-existente entre los sistemas lingüísticos dados:

$$
\mathbf{I x y}=S \cdot \frac{P x P y}{(D x y)^{2}} \cdot \frac{P x}{P x+P y}
$$

$$
\begin{array}{ll}
I=\text { influencia } & I x y=\text { influencia de } x \text { sobre } y \\
P=\text { número de habitantes (población) } & D=\text { distancia } \\
D x y=\text { distancia de } x \text { a } y & S=\text { semejanza lingüística }
\end{array}
$$

Así, por ejemplo, dando a la variable $\mathrm{S}$ los valores de 4 para las variedades de Norfolk, 3 para las de East Anglia, 2 para las del sureste, I para otras variedades de Inglaterra y 0 para el resto, Trudgill obtiene unos índices de influencia lingüística sobre Norwich de las dos ciudades inglesas más grandes, Londres y Birmingham, teniendo en cuenta sus poblaciones, distancia geográfica y posible proximidad de los sistemas lingüísticos, muy ajustados a la realidad:

\section{I $\cdot$ Londres $\cdot$ Norwich $=156$ \\ $\mathrm{I} \cdot$ Birmingham $\cdot$ Norwich $=005$}

lo que sugiere que la influencia lingüística de Londres sobre Norwich es aproximadamente 31 veces mayor que la de Birmingham; esto nos puede ser muy útil a la hora de estudiar el posible origen e influencia que una determinada innovación pueda tener.

Teniendo en cuenta estos modelos de difusión geográfica, podemos ahora planternos, por ejemplo, el caso tratado por los dialectólogos tradicionales sobre la distinción $/ \mathrm{u} /-/ \mathrm{N} /$ que en Gran Bretaña tienen los acentos escoceses y los del sur de Inglaterra, quedando una zona intermedia, las Midlands y el norte de Inglaterra, sin tal distinción. Si bien la solución no es fácil, sí se pueden proponer una serie de preguntas que orienten el problema en otra dirección: esta distinción «¿es el resultado de una innovación distinta aunque casi idéntica? ¿o saltó la innovación surgida en Londres a, digamos, Edimburgo, dejando las zonas inmediatas de las Midlands y el norte inalteradas? ¿o quizás surgió la innovación en Escocia?»; las innovaciones podrían haber aparecido en períodos de tiempo diferentes - cuando la distribución de la población era diferente y la distancia un factor con un distinto peso específico por la diferencia en las condiciones de transporte-, y/o podrían simplemente haber surgido en lugares diferentes, y/o podría haber otros factores lingüísticos a tener en cuenta (Trudgill 1983b: 85). La falta de datos precisos hace que este fenómeno sea enigmático, y por ello ciertamente atractivo e interesante, y que continúe siendo estudiado. 
Por tanto, al igual que la variable linguística, con la ayuda de la teoría y métodos sociológicos, puede perfeccionar nuestro conocimiento de la relación existente entre el lenguaje y la sociedad, también «la variable lingüística, junto con una serie de revelaciones metodológicas y teóricas procedentes de la geografía humana, puede perfeccionar nuestro conocimiento de las relaciones entre el lenguaje y la geografía, y el escenario geográfico del cambio lingüístico»: «una dialectología o geolingüística dinámicas que hagan uso de modelos de difusión geográfica que incorporen el tiempo, y técnicas sociolingüísticas y geográficas que permitan el tratamiento de fenómenos en progreso, pueden describir mejor e incluso explicar algunos de los procesos implicados en la difusión de las innovaciones lingüísticas». (Trudgill 1983b: 87).

\section{CONCLUSIÓN}

La Dialectología Tradicional, la Sociolingüística Laboviana y la Geolingüística Trudgilliana son tres tratamientos diferentes, si bien complementarios (Trudgill 1992a), dirigidos hacia un mismo objeto de estudio: los fenómenos de la variación y el cambio lingüístico. Las aproximaciones desarrolladas por los estudios dialectológicos tradicionales y los geolingüísticos se plantean para grupos sociales en un macro-nivel de interacción mientras que las desarrolladas mediante la investigación puramente laboviana lo hacen para los individuos en un micro-nivel de interacción, aunque actuando las tres dentro del espectro de la macro-sociolingüística. Con sus reproducciones cartográficas descriptivas de las diferencias dialectales, los dialectólogos tradicionales han sido considerados en muchas ocasiones como 'meros coleccionistas de mariposas' e incluso practicantes de una especie de 'arqueología lingüística', sobre todo por el desfase existente en los presupuestos teóricos, objetos de estudio, métodos y técnicas empleadas; pero también es cierto que sin sus descripciones llevadas a cabo entonces antes de que los dialectos regionales tradicionales desaparecieran, no se podría haber hecho uso de esos datos en análisis posteriores como, por ejemplo, los estudios sociolinguísticos de Labov (1966) en Martha's Vineyard y Nueva York y Trudgill (1974a) en Norwich (Trudgill 1992a: 72). Los lingüistas seculares, o sociolingüistas labovianos, le han dado al estudio del lenguaje una dimensión social y cultural, centrando sus investigaciones en las comunidades urbanas, que es donde reside la inmensa mayoría de la población actual, y haciendo uso de unos métodos y técnicas más acordes con el momento. La Geolingüística, aún por desarrollarse, representa la concepción que Trudgill (1983b) propone para estos estudios en la medida en que «lo ideal sería que ambos métodos, el dialectológico y el sociolingüístico, se combinaran»: «una síntesis de los métodos y objetivos de la dialectología tradicional y de los de la linguística secular, o de otras formas de macrosociolingüística, junto con un 
input de la geografía humana» (Trudgill 1992a: 73), de ahí que en otro momento (Trudgill 1983b: 51) la llamara 'dialectología sociolingüísticamente instruida'. No obstante, hemos de ser conscientes de y reconocer que «el cambio lingüístico constituye uno de los grandes misterios sin resolver de la ciencia lingüística, y el enigma de la causa y propósito de éste es un reto con el que generaciones de lingüistas y filólogos han luchado [...] Hemos llegado a ser muy expertos explicando por qué ocurren determinados cambios linguiísticos, y por qué se espera que tengan lugar unos más que otros. Sin embargo, todavía somos muy inexpertos explicando su funcionamiento: ¿por qué determinados cambios ocurren en una variedad linguística concreta en un momento dado, y no en otras variedades u otros momentos?» (Trudgill 1992b: vii). En cualquier caso, como Keith Walters (1988) y Peter Trudgill (1992a) indican, la existencia de estas diferentes líneas de trabajo - independientemente de lo sofisticadas que seanprovocarán considerables avances en el futuro, además de evidenciar la constante y creciente actividad y solidez de los estudios de la variación: por muy enigmáticos y llenos de inconvenientes que estén, el estudio de las situaciones de lenguas y dialectos en contacto, los mecanismos del cambio lingüístico y su difusión, los escenarios sociales y geográficos de éste, la naturaleza de su variabilidad y la estructura de los sistemas lingüísticos, contribuyen a la localización del lenguaje dentro y a través del espacio geográfico, social y temporal, constituyendo puntos de convergencia en el perfeccionamiento de la teoría lingüística $y$, en último término, de nuestro conocimiento de la naturaleza del lenguaje como capacidad humana.

\section{REFERENCIAS:}

ALVAR, M. (1963) «Los Atlas Lingüísticos de España», en PFLE, I, Madrid, 1963. ALVAR, M. (1968) «Estado Actual de los Atlas Linguísticos Españoles», en Actas del XI CILFR, I, Madrid, 1968.

ALVAR, M. (1973) Estructuralismo, Geografía Lingüística y Dialectología Actual. Madrid: Gredos (2ª Edición).

BARTOLI, M. (1925) Introduzione alla Neolinguistica. Geneva: L.S. Olschki. BARTOLI, M. (1945) Saggi di Linguistica Spaziale. Torino: Bond.

BONFANTE, G. (1947) «The Neolinguistic Position», en Language, Vol. 23, 1947, pp. 344-75.

CHAMBERS, J.K. \& TRUDGILL, P.J. (1980) Dialectology. Cambridge: C.U.P. CHESHIRE, J. (1978) «Present Tense Verbs in Reading English», en TRUDGILL (ed) (1978).

FRANCIS, W.N. (1983) Dialectology: An Introduction, New York: Longman.

GILES, H. (1973) «Accent mobility: A Model and Some Data», en Anthropological Linguistics, vol. 15, pp. 87-105. 
GIMENO MENENDEZ, F. (1990) Dialectologia y Sociolingüística Españolas. Alicante: Universidad de Alicante.

GRIERA, A. (1924-) Atlas Lingüistic de Catalunya. Barcelona: Institut d'Estudis Catalans.

HAGGETT, P. (1965) Location Analysis in Human Geography. London: Edward Arnold.

HÄGERSTRAND, T. (1952) «The Propagation of Innovation Waves», en Lund Studies in Geography, Series B, Human Geography 4. Lund: Gleerup.

HORVATH, B. (1985) Variation in Australian English: The Sociolects of Sydney. Cambridge: CUP.

HUGHES, A. \& TRUDGILL, P.J. (1979) English Accents and Dialects: An Introduction to Social and Regional Varieties of British English. London: Arnold. JIMENEZ CANO, J.M. (1992) «Lengua y Generaciones», en G. HOLTUS, M. METZELTIN \& C. SCHMITT (eds) (1992) Lexicon der Romanistischen Linguistik (Vol IV,1: Aragonés/Navarro, Español, Asturiano/Leonés), Tübingen: Max Niemeyer Verlag.

KNOWLES, G.O. (1974) Scouse: the Urban Dialect of Liverpool. University of Leeds: tesis para Ph.D. sin publicar.

KNOWLES, G.O. (1978) «The Nature of Phonological Variables in Scouse», en TRUDGILL (ed) (1978).

KURATH, H. (1972) Studies in Area Linguistics. Bloomington: Indiana University Press.

LABOV, W. (1966) The Social Stratification of English in New York City. Washington, D.C.: Center for Applied Linguistics.

LÓPEZ MORALES, H. (1983) Estratificación Social del Español de San Juan de Puerto Rico. México: Universidad Nacional Autónoma de México.

MACAULAY, R. (1977) Language, Social Class, and Education: A Glasgow Study. Edinburgh: Edinburgh University Press.

MACAULAY, R. (1978) «Variation and Consistency in Glaswegian English», en TRUDGILL (ed) (1978).

MATIAS, M. (1984) Bilinguismo e Níveis Sociolinguísticos numa Região Luso-Espanhola. Coimbra: University of Coimbra.

MILROY, J. \& MILROY, L. (1978) «Belfast: Change and Variation in an Urban Vernacular», en TRUDGILL (ed) (1978).

MILROY, L. (1980) Language and Social Networks (Language in Society Series). Oxford: Basil Blackwell (2 Edición 1989).

OLSSON, G. (1965) Distance and Human Interaction. Philadelphia: Regional Science Research Institute.

REID, E. (1976) Social and Stylistic Variation in the Speech of Some Edinburgh Schoolchildren. University of Edinburgh: tesis para M.Litt. sin publicar.

REID, E. (1978) «Social and Stylistic Variation in the Speech of Children: Some Evidence from Edinburgh», en TRUDGILL (ed) (1978).

ROMAINE, S. (1978) «Postrocalic / $\mathrm{x} /$ in Scottish English: Sound Change in Progress?», en TRUDGILL (ed) (1978), pp. 144-157. 
SANKOFF, G. \& CEDERGREN, H. (1971) «Some Results of a Sociolinguistic Study of Montreal French», en R. DARNELL (ed) (1971) Linguistic Diversity in Canadian Society. Champaign, Ill.: Linguistic Research, Inc.

SELINKER, L. (1972) «Interlanguage», en IRAL, vol. X, 1972, pp. 209-230.

SHUY, R., WOLFRAM, W.A. \& RILEY, W.R. (1967) A Study of Social Dialects in Detroit. Washington, DC: Office of Education.

TRUDGILL, P.J. (1974a) The Social Differentiation of English in Norwich. Cambridge: C.U.P.

TRUDGILL, P.J. (1974b) «Linguistic Change and Difussion: Description and Explanation in Sociolinguistic Dialect Geography», en Language in Society, vol.

3, 1974, pp. 215-246. Una versión revisada en TRUDGILL (1983b), pp. 52-87. TRUDGILL, P.J. (1975) «Linguistic Geography and Geographical Linguistics», en

C. BOARD, R. CHORLEY, P. HAGGET \& D. STODDART (eds) (1975) Progress in Geography: International Reviews in Current Research 7 . London: Edward Arnold. Pp. 227-252.

TRUDGILL, P.J. (ed) (1978) Sociolinguistic Patterns in British English. London: Edward Arnold.

TRUDGILL, P.J. (1983a) Sociolinguistics: An Introduction to Language and Society. London: Penguin (Edición Revisada; 1ª Edición 1974).

TRUDGILL, P.J. (1983b) On Dialect: Social and Geographical Perspectives. Oxford: Blackwell.

TRUDGILL, P.J. (1986) Dialects in Contact (Language in Society Series). Oxford: Blackwell.

TRUDGILL, P.J. (1990) The Dialects of England. Oxford: Blackwell.

TRUDGILL, P.J. \& CHAMBERS, J.K. (eds) (1991) Dialects of English: Studies in Grammatical Variation. New York: Longman.

TRUDGILL, P.J. (1992a) «Dialect Contact, Dialectology and Sociolinguistics», en BOLTON, K. \& KWOK, H. (eds) (1992) Sociolinguistics Today: International Perspectives. London: RKP. Pp. 71-79.

TRUDGILL, P.J. (1992b) «Editor's Preface», en J. MILROY (1992) Linguistic Variation \& Change (Language in Society Series, 19). Oxford: Basil Blackwell. WALTERS, K. (1988) «Dialectology», en F.J. NEWMEYER (ed) (1988), Linguistics: The Cambridge Survey (vol IV). Cambridge: CUP. Pp. 119-139.

WELLS, J.C. (1982) Accents of English (3 Vols). Cambridge: CUP.

WOLFRAM, W. (1971) «Black-White Speech Differences Revisited», en WOLFRAM \& CLARKE (eds) (1971) Black-White Speech Relationships. Washington, DC: Center for Applied Linguistics. 